\title{
Crescimento e produção de cumarina em plantas de chambá (Justicia pectoralis Jacq.) tratadas com isoterápico
}

\author{
ANDRADE, F.M.C.*; CASALI, V.W.D.; CECON, P.R.C. \\ Universidade Federal de Viçosa-Departamento de Fitotecnia, Campus da UFV, s/n, CEP: 36570-000, Viçosa- \\ Brasil *fernandamcandrade@hotmail.com
}

\begin{abstract}
RESUMO: Este trabalho teve por objetivo avaliar a resposta a dinamizações do isoterápico Justicia no crescimento e na produção de cumarina em Justicia pectoralis. O experimento foi conduzido na Universidade Federal de Viçosa. O delineamento estatístico foi inteiramente casualizado, com quatro repetições e seis tratamentos, totalizando 24 parcelas experimentais, sendo cada parcela constituída de uma planta por vaso. Os tratamentos foram constituídos das dinamizações $3 \mathrm{CH}, 6 \mathrm{CH}, 12 \mathrm{CH}, 18 \mathrm{CH}, 24 \mathrm{CH}$ e $30 \mathrm{CH}$, do isoterápico Justicia. A aplicação dos tratamentos iniciou após o plantio das mudas, sendo pulverizada a parte aérea, em intervalos semanais. Após quatro meses do plantio as plantas foram colhidas. Foram avaliadas a matéria fresca e seca das folhas e caules a matéria fresca e seca da inflorescência, e a matéria fresca e seca total. Foram pesadas amostras de $200 \mathrm{mg}$ das folhas e caules das plantas secas. As amostras foram devidamente armazenadas até a realização das análises químicas. A quantificação da cumarina (1-2 benzopirona) nas amostras foi feita em Cromatógrafo Líquido de Alta Eficiência. A matéria fresca de folhas e caules, a matéria fresca total e o rendimento de cumarina variaram em função das dinamizações do isoterápico. Os resultados confirmam o efeito de preparações homeopáticas na planta demonstrando que a homeopatia nos vegetais, mesmo na Lei da Igualdade tem efeitos potenciais.
\end{abstract}

Palavras-chave: Justicia pectoralis, homeopatia, dinamizações

\begin{abstract}
Growth and production of coumarin in the plants of chambá (Justicia pectoralis Jacq.) treated with isoterapic. The studied aimed to evaluate the responses to dynamizations of Justicia isoterapic in growth and coumarin production in Justicia pectoralis. The studies were carried out at the Universidade Federal de Viçosa. The statistical design was completely randomized, with four replicates and six treatments, 24 experimental plots, one plant per pot. The treatment were dynamizations $3 \mathrm{CH}, 6 \mathrm{CH}, 12 \mathrm{CH}, 18 \mathrm{CH}, 24 \mathrm{CH}$ and $30 \mathrm{CH}$ Justicia isoterapic. The applications of the treatments begun are planting seedlings, the aerial part being sprayed, at weekly intervals. After four months of planting, the plants were harvested. Were evaluated fresh and dry matter of stem and leaves, fresh and dry matter of inflorecense, and fresh and dry matter total. Were weighed samples on $200 \mathrm{mg}$ of leaves and stems of dried plants. The samples were properly stored at quimical analyses. The quantification of coumarin (1-2 benzopyrone) in the samples was done in High Resolution Liquid Chromatography. The fresh matter of leaves and stems, the fresh matter total and a production of coumarin varied as a function of dynamization of isoterapic. The results confirm the effect of homeopathics preparations in the plants demonstrating that homeopathy in vegetables even in the Equality Law has potential effect.
\end{abstract}

Key words: Justicia pectoralis, homeopathy, dynamizations

\section{INTRODUÇÃO}

Justicia pectoralis Jacq., Acanthaceae, conhecida popularmente no Nordeste do Brasil como chambá, é utilizada tradicionalmente no tratamento de doenças do trato respiratório como asma, tosse e bronquite (Agra et al., 2007). Segundo Fonseca et al.
(2010), as cumarinas são o metabólito secundário majoritário da espécie e responsável pela ação terapêutica.

A espécie $J$. pectoralis encontra-se na Relação Nacional de Plantas Medicinais de Interesse

Recebido para publicação: setembro de 2011

Aceito para publicação: março de 2012

Rev. Bras. PI. Med., Botucatu, v.14, especial, p.154-158, 2012. 
pelo SUS (Ministério da Saúde, 2008), sendo prioridade pesquisá-la.

$\mathrm{Na}$ produção de plantas medicinais e aromáticas, os sistemas orgânicos de cultivo são os mais indicados (Pedrosa et al., 2010). No cultivo das espécies medicinais a homeopatia traz muitos benefícios em toda cadeia produtiva, sendo tecnologia simples, barata, eficiente e promissora (Casali et al., 2010). O cultivo de plantas medicinais com homeopatia permite a inserção de agricultores familiares, diversificando as atividades de renda e agregando valor a produção (Andrade \& Casali, 2011).

A aplicação de preparados homeopáticos causa resposta no metabolismo das plantas podendo diminuir ou aumentar compostos bioativos de grande importância social e de valor no mercado, dependendo da dinamização aplicada (Duarte, 2007). Além disso, por serem as preparações homeopáticas ultradiluídas não deixam resíduos nas plantas favorecendo a produção de plantas com qualidade biológica (Casali et al., 2010). Na Homeopatia os preparados são escolhidos segundo o princípio da semelhança. Deste modo, são estabelecidas as analogias entre os quadros de desequilíbrio e a patogenesia das preparações homeopáticas. Entretanto, na Homeopatia também é adotado o princípio dos iguais, na escolha do preparado homeopático, desde que as preparações sejam manipuladas segundo as regras da Farmacotécnica Homeopática (Arruda et al., 2005).

Os preparados homeopáticos denominados isoterápicos agem segundo a Lei dos Iguais, ou seja, os iguais se equilibram pelos iguais. Duarte (2003) constatou que o isoterápico feito de mentrasto quando aplicado a plantas de mentrasto (Ageratum conyzoides L.), causa alteração no conteúdo de óleo essencial, sem, no entanto, interferir sobre o crescimento e a produção das plantas.

No meio rural geralmente a primeira opção experimentada pela família agrícola são os isoterápicos, como o caso dos nosódios. Nas plantas os isoterápicos promove a reação/defesa das plantas (Casali et al., 2002), sendo opção acessível por ser produzido com recursos locais (Andrade et al., 2010).

Este trabalho teve por objetivo avaliar a resposta às crescentes dinamizações do isoterápico Justicia no crescimento e produção de cumarina em Justicia pectoralis.

\section{MATERIAL E MÉTODO}

\section{Obtenção das plantas}

As mudas foram propagadas por divisão de touceiras de plantas matrizes pertencentes ao Grupo Entre Folhas, em Viçosa-MG, sendo diretamente plantadas em vasos de 3,0 litros, contendo como substrato terra colhida sob mata, sem adubação. A exsicata encontra-se no Herbário VIC do Departamento de Biologia Vegetal da Universidade Federal de Viçosa (UFV), identificada pelo número VIC 23581.

\section{Condução do experimento}

O experimento foi conduzido em casa de vegetação, com tela de $30 \%$ de sombreamento e cobertura de filme transparente de polietileno, na Universidade Federal de Viçosa, durante o período de junho a outubro de mil novecentos e noventa e nove.

O delineamento estatístico foi inteiramente casualizado, com quatro repetições e seis tratamentos, totalizando 24 parcelas experimentais, sendo cada parcela constituída de uma planta por vaso.

Os vasos de cada tratamento foram distanciados de $3 \mathrm{~m}$, isolados com filme de polietileno transparente e distribuídos aleatoriamente, sendo feito rodízio quinzenalmente.

Os tratamentos foram constituídos das dinamizações $3,6,12,18,24$ e 30, na escala centesimal hahnemaniana $(\mathrm{CH})$ do isoterápico Justicia.

O preparado isoterápico Justicia foi elaborado, a partir da tintura mãe feita com a espécie J. pectoralis, utilizando a parte aérea da planta, seguindo normas padronizadas (Dôres et al., 2007).

A implementação dos tratamentos iniciou logo após o plantio. Foi preparada uma solução contendo 10 gotas da homeopatia/litro de água desmineralizada sendo pulverizado aproximadamente 2,65 mL na parte aérea das plantas, em intervalos semanais, nas primeiras horas do dia. Foi adotado o procedimento "Duplo Cego", que consiste em ocultar, por meio de códigos, a identificação dos tratamentos, durante toda a aplicação e avaliação do experimento.

\section{Análise do crescimento}

As plantas foram colhidas com tesoura de poda quando em pleno florescimento, quatro meses após o plantio. Imediatamente após a colheita, foi determinado em balança semi - analítica o peso da matéria fresca das folhas e caules, das inflorescências, e o peso da matéria fresca total. Após a determinação da matéria fresca, as plantas foram embaladas em sacos de papel "Kraft", devidamente identificados e conduzidas à câmara de secagem. As plantas foram secas em sala com desumidificador (capacidade 18 $\mathrm{L}$ dia $^{-1} 280 \mathrm{~m}^{-3}$, circulação $60 \mathrm{~m}^{2} / \mathrm{h}, 390$ watts) com temperatura entre 15,4 e $20,9^{\circ} \mathrm{C}$, até atingirem peso constante, quando foram pesadas em balança semianalítica, obtendo-se o peso da matéria seca das folhas e caules, das inflorescências e o peso da matéria seca total.

Os dados foram submetidos à análise de variância (ANOVA) e as médias comparadas,

Rev. Bras. PI. Med., Botucatu, v.14, n.esp., p.154-158, 2012. 
utilizando-se o teste de Tukey a 5\% de probabilidade.

\section{Extração e quantificação da cumarina}

A extração e a quantificação das cumarinas foram realizadas no Laboratório de Análise e Síntese de Agroquímicos do Departamento de Química da Universidade Federal de Viçosa.

Foram pesadas amostras de $200 \mathrm{mg}$ das folhas e caules de cada planta seca, que foram trituradas em moinho Marconi, modelo TE 048 e submetidas a três extrações a quente $\left(65^{\circ} \mathrm{C}\right)$, em 7 $\mathrm{mL}$ de metanol, e após filtragem foram concentradas em evaporador rotativo, obtendo-se resíduo verde escuro.

O resíduo obtido foi dissolvido em $10 \mathrm{~mL}$ de água destilada e $10 \mathrm{~mL}$ de diclorometano. A fase orgânica foi separada por meio de funil de separação, sendo em seguida seca sobre sulfato de magnésio anidro. Após filtração a vácuo, as amostras foram armazenadas em vidros vedados com parafilme e mantidas ao abrigo da luz em temperatura de $\left(-10^{\circ} \mathrm{C}\right)$, até o momento da quantificação das cumarinas em Cromatógrafo Líquido de Alta Eficiência (HPLC).

As amostras obtidas na extração e armazenadas à baixa temperatura $\left(-10^{\circ} \mathrm{C}\right)$ tiveram o volume completado à $5 \mathrm{~mL}$ com diclorometano. Deste volume retirou-se $200 \mu \mathrm{L}$ e adicionou-se $2 \mathrm{~mL}$ de diclorometano, obtendo-se a amostra utilizada na quantificação da cumarina.

A quantificação da cumarina (1,2benzopirona) nas amostras foi realizada em HPLC. $O$ volume injetado de amostra foi de $20 \mu \mathrm{L}$, utilizando como fase móvel acetato de etila:hexano (3:1), com fluxo de $1,2 \mathrm{~mL} \mathrm{~min}^{-1}$.

Com base em procedimentos de ajuste, o tempo de retenção da cumarina foi aproximadamente 5,3 minutos e a concentração nas amostras foi calculada mediante a curva padrão obtida pela injeção no HPLC de soluções padrão de 1,2-benzopirona (Merck), em concentrações conhecidas de 0, 2, 4, 6, 8 e $10 \mathrm{ppm}$.
Os dados foram interpretados por meio de análise de variância e regressão. Os modelos foram escolhidos baseados na significância dos coeficientes de regressão utilizando-se o teste de "t" ao nível de $5 \%$ de probabilidade.

\section{RESULTADO E DISCUSSÃO}

Foi verificada resposta significativa às crescentes dinamizações de Justicia, nas variáveis de crescimento: matéria fresca de folhas e caules e matéria fresca total (Tabela 1).

A matéria fresca de folhas e caules e a matéria fresca total variaram em função das dinamizações de Justicia, ora aumentando ora diminuindo (Tabela 2). Em 3CH houve produção baixa que aumentou em $6 \mathrm{CH}$ caindo novamente em $12 \mathrm{CH}$, atingindo o mínimo em $18 \mathrm{CH}$ e posteriormente aumentando em $24 \mathrm{CH}$, atingindo a produção máxima em $30 \mathrm{CH}$.

Armond et al. (2005) verificaram que crescentes dinamizações de China interferem no peso da matéria fresca da parte aérea de picão (Bidens pilosa L.). O tratamento que proporcionou maior peso foi $24 \mathrm{CH}$ e os menores foram $12 \mathrm{CH}, 14 \mathrm{CH}$ e $18 \mathrm{CH}$. Os resultados conferem com os verificados neste ensaio. Entretanto, a dinamização $30 \mathrm{CH}$ de Justicia foi a que causou maior massa fresca de folhas e caules e massa fresca total de J. pectoralis, no entanto, esta dinamização não foi testada em picão.

$O$ rendimento de cumarina também variou em função da dinamização de Justicia (Figura 1), ora aumentando ora diminuindo. A equação de regressão ajustada foi:

$Y=0,349832+0,00698007$ * ${ }^{\text {Din }-}$ $0,000551195^{* *} \operatorname{Din}^{2}+0,0000106228^{* *} \operatorname{Din}^{3}\left(R^{2}=0,8677\right)$

Na Figura 1 observam-se os picos de produção nas dinamizações $6 \mathrm{CH}$ e $12 \mathrm{CH}$, seguidas de redução em $18 \mathrm{CH}$ e $24 \mathrm{CH}$ e aumento em $30 \mathrm{CH}$.

Os resultados confirmam o fenômeno de

TABELA 1. Resumo da análise de variância das variáveis: matéria fresca de folha e caule (MFFC), matéria fresca da inflorescência (MFI), matéria fresca total (MFT), matéria seca de folha e caule (MSFC), matéria seca de inflorescência (MSI) e matéria seca total (MST) de Justicia pectoralis, colhida no ensaio conduzido no período de junho a outubro de 1999, realizado em Viçosa-MG

\begin{tabular}{lccccccc}
\hline \multirow{2}{*}{ F.V. } & \multirow{2}{*}{ G.L. } & \multicolumn{9}{c}{ Quadrado Médio } \\
\cline { 3 - 7 } & & MFFC & MFI & MFT & MSFC & MSI & MST \\
\hline Tratamento & 5 & $16,5439^{* *}$ & $1,2288^{\text {ns }}$ & $23,2395^{* *}$ & $33,5946^{\text {ns }}$ & $8,4858^{\text {ns }}$ & $47,0154^{\text {ns }}$ \\
Resíduo & 18 & 3,1354 & 1,8583 & 3,5060 & 27,0181 & 8,8033 & 40,0101 \\
C.V. (\%) & & 18,53 & 39,01 & 14,34 & 18,12 & 9,09 & 10,32 \\
\hline
\end{tabular}

ns - $\mathrm{F}$ não-significativo a $5 \%$ de probabilidade. ${ }^{* *}$ - $\mathrm{F}$ significativo a $1 \%$ de probabilidade. 
TABELA 2. Efeito das crescentes dinamizações de Justicia na matéria fresca de folha e caule (MFFC), matéria fresca da inflorescência (MFI), matéria fresca total (MFT), matéria seca de folha e caule (MSFC), matéria seca de inflorescência (MSI) e matéria seca total (MST) de Justicia pectoralis, colhida no ensaio conduzido no período de junho a outubro de 1999, realizado em Viçosa-MG

\begin{tabular}{lcccccc}
\hline Tratamentos & $\begin{array}{c}\text { MFFC } \\
\text { (g/planta) }\end{array}$ & $\begin{array}{c}\text { MFI } \\
\text { (g/planta) }\end{array}$ & $\begin{array}{c}\text { MFT } \\
\text { (g/planta) }\end{array}$ & $\begin{array}{c}\text { MSFC } \\
\text { (g/planta) }\end{array}$ & $\begin{array}{c}\text { MSI } \\
\text { (g/planta) }\end{array}$ & $\begin{array}{c}\text { MST } \\
\text { (g/planta) }\end{array}$ \\
\hline $3 \mathrm{CH}$ & $9,20 \mathrm{ab}$ & $3,28 \mathrm{a}$ & $12,48 \mathrm{ab}$ & $2,72 \mathrm{a}$ & $1,04 \mathrm{a}$ & $3,76 \mathrm{a}$ \\
$6 \mathrm{CH}$ & $10,80 \mathrm{a}$ & $3,05 \mathrm{a}$ & $13,85 \mathrm{a}$ & $3,10 \mathrm{a}$ & $0,96 \mathrm{a}$ & $4,06 \mathrm{a}$ \\
$12 \mathrm{CH}$ & $10,20 \mathrm{ab}$ & $3,81 \mathrm{a}$ & $14,02 \mathrm{a}$ & $2,47 \mathrm{a}$ & $1,29 \mathrm{a}$ & $3,76 \mathrm{a}$ \\
$18 \mathrm{CH}$ & $6,24 \mathrm{~b}$ & $2,98 \mathrm{a}$ & $8,97 \mathrm{~b}$ & $1,98 \mathrm{a}$ & $0,98 \mathrm{a}$ & $3,21 \mathrm{a}$ \\
$24 \mathrm{CH}$ & $8,70 \mathrm{ab}$ & $3,99 \mathrm{a}$ & $12,69 \mathrm{ab}$ & $2,64 \mathrm{a}$ & $1,31 \mathrm{a}$ & $3,96 \mathrm{a}$ \\
$30 \mathrm{CH}$ & $12,17 \mathrm{a}$ & $4,09 \mathrm{a}$ & $16,27 \mathrm{a}$ & $3,23 \mathrm{a}$ & $1,29 \mathrm{a}$ & $4,52 \mathrm{a}$ \\
\hline
\end{tabular}

As médias seguidas de pelo menos uma mesma letra na coluna, não diferem entre si, a $5 \%$ de probabilidade, pelo teste de Tukey

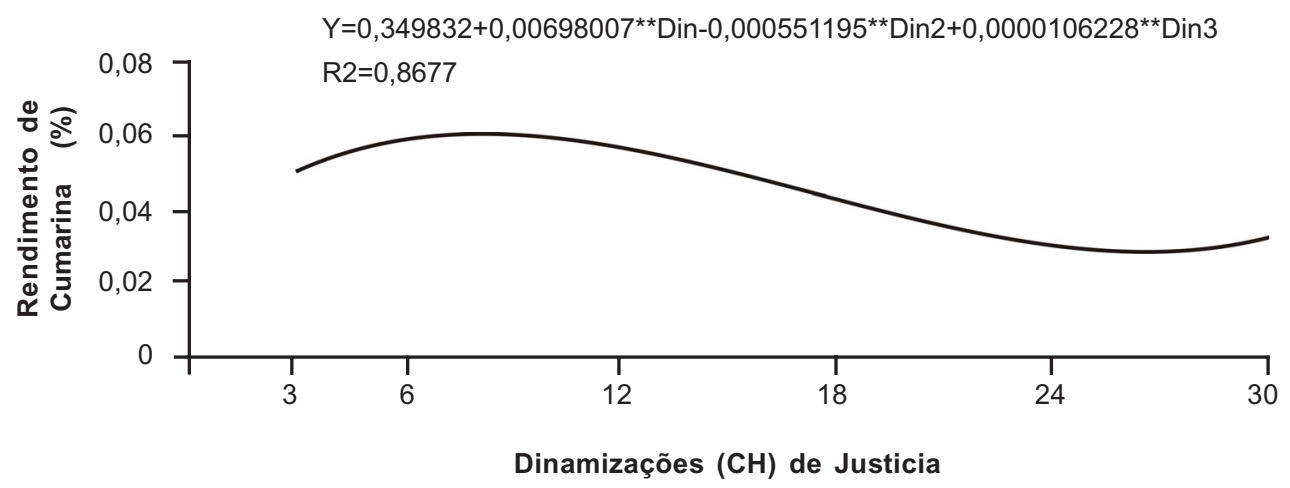

FIGURA 1. Rendimento de cumarina em função de dinamizações de Justicia, em Justicia pectoralis. Viçosa, UFV, 1999.

oscilação das respostas em função da dinamização conforme verificado e discutido em muitas pesquisas (Kolisko \& Kolisko, 1978; Andrade, 2000; Armond et al., 2005).

Segundo Duarte et al. (2005), o preparado homeopático isoterápico Mentrasto causa alteração no teor de óleo essencial de plantas de mentrasto (Ageratum conyzoides L.), sendo verificado o fenômeno da oscilação das respostas em função da dinamização.

Houve concomitância do crescimento em matéria fresca com o conteúdo de cumarina. As plantas com maior crescimento produziram menor conteúdo de cumarina. Este resultado pode ser devido ao efeito de diluição do metabólito. $\mathrm{Em} 30 \mathrm{CH}$ as plantas produziram mais matéria fresca e apresentaram teores mais baixos de cumarina em relação aos outros tratamentos. Entretanto, em $30 \mathrm{CH}$ há retomada na produção da cumarina. Provavelmente as plantas perceberam o fator externo, reagindo defensivamente. O maior rendimento de cumarina foi alcançado em $6 \mathrm{CH}$, porém com baixa produção de matéria fresca comparada a $30 \mathrm{CH}$.

O aumento do crescimento e diminuição da defesa pode expressar a retomada à homeostase, levando sempre ao equilíbrio na distribuição da energia entre crescimento e defesa, conforme discutido por Martins (1996).

O aumento do crescimento e a retomada da produção de cumarina em $30 \mathrm{CH}$ demonstram que essa dinamização foi percebida pelas plantas com alterações marcantes. Portanto, J. pectoralis respondeu às preparações de Justicia variando significativamente o metabólito de defesa.

Estes resultados confirmam o efeito de preparações homeopáticas não moleculares na planta, demonstrando que a homeopatia nos vegetais, mesmo na Lei da Igualdade, tem efeitos potenciais.

\section{AGRADECIMENTO}

Ao CNPq, aos Departamentos de Fitotecnia, Química e Informática da Universidade Federal de Viçosa. 


\section{REFERÊNCIA}

AGRA, M.F.; FREITAS, P.F.; BARBOZA FILHO, J.M. Synopsis of the plants known as medicinal and poisonous in northeast of Brazil. Revista Brasileira de Farmacognosia, v.17, p.114-40, 2007.

ANDRADE, F.M.C. Homeopatia no crescimento e na produção de cumarina em chambá Justicia pectoralis Jacq. 2000. 214p. Dissertação (Mestrado-Área de Concentração em Fitotecnia) - Departamento de Fitotecnia, Universidade Federal de Viçosa, Viçosa.

ANDRADE, F.M.C.; CASALI, V.W.D.; CUPERTINO, M.C. Seleção de indicadores, monitoramento e sistematização de experiências com homeopatia em unidades agrícolas familiares. Revista Brasileira de Agroecologia, v.5, n.1, p.61-73, 2010.

ANDRADE, F.M.C.; CASALI, V.W.D. Homeopatia, agroecologia e sustentabilidade. Revista Brasileira de Agroecologia, v.6, n.1, p.49-56, 2011.

ARMOND, C. et al. Teor de óleo essencial e compostos antimaláricos em Bidens pilosa L. tratadas com a homeopatia China. Revista Brasileira de Plantas Medicinais, v.7, n.3, p.18-24, 2005.

ARRUDA, V.M. et al. Homeopatia tri una na agronomia. Viçosa: UFV, 2005. 120p.

CASALI, V.W.D.; CASTRO, D.M.; ANDRADE, F.M.C. Pesquisa sobre homeopatia nas plantas. In: SEMINÁRIO BRASILEIRO SOBRE HOMEOPATIANAAGROPECUÁRIA ORGÂNICA, 3., 2001, Campinas do Sul. Anais... Viçosa: UFV, 2002. p.16-25.

CASALI, V.W.D. et al. Benefícios da homeopatia no cultivo de plantas medicinais. Informe Agropecuário, v.31, p.7984, 2010.

DÔRES, R.G.R.; ANDRADE, F.M.C.; CASALI, V.W.D. Manipulação de preparados homeopáticos. Viçosa: UFV, 2007. 164p.
DUARTE, E.S.M. Soluções homeopáticas, crescimento e produção de compostos bioativos em Ageratum conyzoides L. (Asteraceae). 2003. 92p. Dissertação (Mestrado-Área de Concentração em Fitotecnia) Departamento de Fitotecnia, Universidade Federal de Viçosa, Viçosa.

DUARTE, E.S.M. et al. Aplicação de preparados homeopáticos (isoterápicos) na produção de óleo essencial em plantas de mentrasto (Ageratum conyzoides L.). In: SEMINÁRIO BRASILEIRO SOBRE HOMEOPATIANAAGROPECUÁRIAORGÂNICA, 6., 2004, Nova Venécia. Anais...Viçosa: UFV, 2005. p.199-208.

DUARTE, E.S.M. Crescimento e teor de óleo essencial em plantas de Eucalyptus citriodora e Eucalyptus globulus tratadas com homeopatia. 2007. 188p. Tese (Doutorado-Área de Concentração em Fitotecnia) Departamento de Fitotecnia, Universidade Federal de Viçosa, Viçosa.

FONSECA, F.N.; SILVA, A.H.; LEAL, L.K.A.M. Justicia pectoralis Jacq., Acanthaceae: preparation and caracterisation of the plant drug including chromatographic analyses by HPLC-PDA. Revista Brasileira de Farmacognosia, v.20, p.871-7, 2010.

KOLISKO, E.; KOLISKO, L. Agriculture of tomorrow. England: Acorn Press., 1978. 321p.

PEDROSA, M.W. et al. Orientações gerais para cultivo orgânico e hidropônico de plantas medicinais e aromáticas. Informe Agropecuário, v.31, p.57-67, 2010. MARTINS, E.R. Morfologia interna e externa, caracterização isozimática e óleo essencial de Ocimum selloi Benth. 1996. 97p. Dissertação (Mestrado- Área de Concentração em Fitotecnia) - Departamento de Fitotecnia, Universidade Federal de Viçosa, Viçosa.

MINISTÉRIO DA SAÚDE 2008. Relação Nacional de Plantas Medicinais de interesse para o SUS. Disponível em: <http://portal.saude.gov.br/portal/arquivos/pdf/ RENISUS.pdf.>. Acesso em: 20 Mai. 2009. 